\title{
BIENES PÚBLICOS, PROPIEDAD PRIVADA Y NUEVA CONSTITUCIÓN \\ (primera parte)
}

FRANCISCO ZÚÑIGA URBINA

FELIPE PEROTI DÍAZ 
SUMARIO

I. INTRODUCCIÓN: LAS TRANSFORMACIONES DEL ESTADO DE DERECHO, EL RÉGIMEN JURÍDICO DE LA PROPIEDAD Y LOS BIENES PÚBLICOS. 1.1. Del Estado liberal de derecho al Estado social de derecho. 1.2. El tránsito del Estado social (legislativo) al Estado social y democrático de derecho. II. LA REGULACIÓN CONSTITUCIONAL DE LA PROPIEDAD Y EL RÉGIMEN JURÍDICO DE LOS BIENES PÚBLICOS. 2.1. Antecedentes histórico - jurídicos del derecho de propiedad y de los bienes públicos en el ordenamiento constitucional. 2.2. El fundamento constitucional de los bienes públicos y el derecho a la propiedad. 2.3. El artículo $19 \mathrm{~N}^{\circ} 23$ de la CPR: el ámbito de protección del derecho fundamental. III. LA LIMITACIÓN CONSTITUCIONAL A LA LIBRE APROPIABILIDAD DE BIENES Y EL DOMINIO PÚBLICO EN LA CONSTITUCIÓN. 3.1. Antecedentes histórico-jurídicos de la regulación constitucional de los bienes públicos. 3.2. El régimen jurídico de los bienes públicos y su recepción en la Constitución vigente. 3.3. Sobre el concepto y la naturaleza jurídica del dominio público. 3.4. Los elementos característicos del dominio público y las categorías de bienes de dominio público. IV. BIENES PÚBLICOS Y CONCESIÓN DEMANIAL. 4.1. Concesión o permiso demanial: concepto y clasificación. 4.2. Notas características. V.PODER CONSTITUYENTE, LA PROPIEDAD Y EL RÉGIMEN JURÍDICO DE LOS BIENES PÚBLICOS. 5.1. Concepto, titularidad y naturaleza jurídica del poder constituyente. 5.2. Nueva Constitución y el régimen de concesiones sobre BNUP: alcances y efectos. 6. CONCLUSIONES. 


\title{
BIENES PÚBLICOS, PROPIEDAD PRIVADA Y NUEVA CONSTITUCIÓN (primera parte)
}

\author{
FRANCISCO ZÚÑIGA URBINA* \\ FELIPE PEROTI DÍAZ**
}

\section{INTRODUCCIÓN: LAS TRANSFORMACIONES DEL ESTADO DE DERECHO, EL RÉGIMEN JURÍDICO DE LA PROPIEDAD Y LOS BIENES PÚBLICOS}

\subsection{Del Estado liberal de derecho al Estado social de derecho}

El ámbito de protección y el contenido de los derechos fundamentales, resulta indisociable del despliegue histórico de las formas de Estados y los regímenes políticos operados en los ordenamientos constitucionales occidentales en los últimos dos siglos ${ }^{1}$. De hecho, el tránsito del Estado liberal de derecho a un Estado social de derecho ha devenido en un sinnúmero de profundas transformaciones en la estructura estatal, la relación del Estado con la sociedad civil y la interacción de ésta y el aparato estatal con el entorno natural, proceso que inexorablemente ha impactado en el contenido, alcances y garantía de los derechos fundamentales².

El presupuesto básico del Estado liberal de derecho y las constituciones que bajo dicha forma de Estado se dictaron — surgidas en las postrimerías del siglo XVIII, y que luego se difundirían durante buena parte del siglo XIX como el resultado más preclaro del triunfo del constitucionalismo liberal — fue la consagración de normas

* Abogado, Universidad de Chile. Profesor Titular del Departamento de Derecho Público de la Facultad de Derecho. Universidad de Chile. Email: fzuniga@zcabogados.cl

** Abogado, Universidad de Chile. Académico instructor adscrito al Departamento de Derecho Público de la Facultad de Derecho. Universidad de Chile. Secretario de Redacción de la Revista de Derecho Público de la misma Universidad. Email: fperoti@derecho.uchile.cl

1 Sobre el desarrollo de la categoría del Estado de Derecho en nuestra Constitución: Marshall, Pablo. (2010). «El Estado de Derecho como principio y su consagración en la Constitución Política». Revista de Derecho de la Universidad Católica del Norte, Año 17, Nº2, págs. 185 - 204.

2 Nogueira, Humberto. (2003). «El constitucionalismo contemporáneo y los derechos económicos, sociales y culturales». Estudios Constitucionales, Año 1, No1, págs. 135 - 177.

(C) UNED. Revista de Derecho Político 
organizativas del poder público y normas de conducta con especial atención en la regulación de la Administración ${ }^{3}$, y cuyas garantías más sobresalientes es el principio de legalidad como regla atributiva de poder, así como garantía de la libertad y regla de protección en la protección de los derechos individuales ${ }^{4}$. A su vez, la preeminencia de los derechos de libertad o de no interferencia, va aparejada con el desarrollo de un Estado de derecho formal, cuya viga maestra es la primacía de Ley como instrumento privilegiado para la defensa reforzada de la propiedad y la libertad ${ }^{5}$.

Ahora bien, la emergencia provocada por la aparición de carencias sociales básicas en naciones industrializadas y en países en vías de desarrollo, así como la creciente generalización de los derechos de participación política a diversos sectores sociales marginados, demostraron la insuficiencia de dicha estructura constitucional de la democracia liberal, del Estado mínimo y del sistema económico imperante ${ }^{6}$. Ante ello, los estados de finales del siglo XIX propiciaron la aparición de instituciones públicas de beneficencia y de técnicas administrativas de corte asistencial que proveyeron de una primera respuesta ante las apremiantes necesidades que afectaban a importantes grupos sociales, delineando la trayectoria por sobre la cual se llevaría a cabo la realización del Estado social ${ }^{7}$.

En este sentido, la formulación del concepto de Estado social de derecho pretende representar la evolución de una forma de Estado que sigue siendo un Estado garantista del individuo frente al poder y el intercambio con los demás ciudadanos —Estado de derecho- pero es también un Estado comprometido con la promoción del bienestar de la sociedad y de forma especial con la de aquellos sectores más desfavorecidos de la misma - Estado social- como consecuencia del proceso de democratización del Estado en que se incorporan al proceso político una nueva clase social representada por los partidos políticos obreros y de clase media, y la extensión del sufragio a

\footnotetext{
3 Como lo recordaba Otto Mayer en su clásico Derecho Administrativo Alemán señalaba: «La organización del poder público, que caracteriza al régimen de derecho, tiene por fin someter las relaciones entre el Estado y el súbdito a las formas jurídicas». Nótese el énfasis sobre dos de los pilares del Estado de Derecho: la articulación legal del poder, organizando su estructura y ejercicio, así como la existencia de un régimen capaz de circunscribir las relaciones de poder entre la máquina estatal y la persona. Mayer, Otto. (1982). Derecho Administrativo Alemán, Tomo I, Parte General, Buenos Aires, Ediciones Depalma, pág. 139.

4 Jesch, Dietrich. (1978). Ley y Administración: Estudios de la evolución del principio de legalidad, Madrid, Instituto de Estudios Administrativos, págs. 38 - 45. También véase Cruz Villalón, Pedro. (1989). «Formación y evolución de los derechos fundamentales». Revista Española de Derecho Constitucional, año 9, N²5, pág. 49.

5 Böckenförde, Ernst. (2000). Estudios sobre el Estado de Derecho y la Democracia, Madrid, Editorial Trotta, págs. 24 - 26. En el mismo sentido, Ferrajoli, Luigi. (1995). Derecho y razón, Madrid, Editorial Trotta, págs. $860-861$.

6 Sousa Santos de, Boaventura. (2001). «Los derechos humanos en la posmodernidad», en Alonso, M. y Ramírez, J., Ciudadanía y derechos humanos sociales, Medellín, Escuela Nacional Sindical, págs. $172-173$.

Pisarello, Gerardo (2001). «Del Estado Social Legislativo al Estado Social Constitucional: por una protección compleja de los derechos sociales». Isonomía, Nº15, pág. 82.
} 
amplios sectores de la sociedad (analfabetos, mujeres y personas en situación de discapacidad $)^{8}$.

De hecho, como lo recuerda un autor, el Estado social asume el compromiso de no asistir pasivamente al conflicto entre individuos y clases en el terreno económico y social, interviniendo en ese ámbito con vista de asegurar a todos los ciudadanos un mínimo de bienestar, resguardándolos del paro, de la enfermedad, y en general de la miseria. Para lograr esos objetivos, sin embargo, el Estado social no pretende cambiar radicalmente la estructura económica general, sino sólo corregir en lo posible sus disfuncionalidades para lo cual emplea diversos medios, como la implementación de regímenes impositivos de carácter progresivo, la asunción del Estado de la previsión y asistencia social, y la expropiación (previa indemnización) de ciertos bienes o medios de producción que los poderes públicos deciden someter a la gestión pública, quedando a salvo aunque limitados los derechos de propiedad privada, así como la libre iniciativa económica privada?

Como resultado de los profundos cambios operados en el Estado de derecho y sus repercusiones político-institucionales, surge el denominado «constitucionalismo social ${ }^{10}$ », en oposición o en superación del constitucionalismo liberal en que los derechos sociales irrumpirán en el escenario de la dogmática de los derechos fundamentales, incorporándose al listado de los clásicos derechos de libertad en las constituciones ${ }^{11}$. Este proceso de normativización permitió el asentamiento paulatino y el despliegue del denominado Estado social de corte legislativo provocando profundas transformaciones al Estado liberal; ya que sin suprimir la autonomía individual implicó la legitimación de la intervención pública — publificando ciertas actividades económicas - cuya finalidad esencial fue la provisión discrecional de prestaciones por parte del Estado. Entre las principales características del constitucionalismo social podemos mencionar el reconocimiento de los derechos a la organización profesional, la huelga, a la contratación colectiva, al acceso a la propiedad, la aparición de los derechos prestacionales con cargo al Estado, como la educación, la vivienda,

8 Pérez Royo, Javier y Carrasco Durán, Manuel. (2018). Curso de Derecho Constitucional, Madrid, Marcial Pons, pág. 145. Como recuerda Viera, fue Hermann Heller quien formuló teóricamente la noción de Estado social de derecho. Viera, Christian. (2014). «Estado social como fórmula en la Constitución chilena». Revista de Derecho, Universidad Católica del Norte, Año 21, N², págs. 456-457. Sobre este tema, resultan fundamentales, Heller, Hermann (1985). «¿Estado de derecho o dictadura?» y «Europa y el fascismo», en Escritos Políticos, Madrid, Alianza Editorial, págs. 283-301 y págs. 21-132. Véase también, Heller, Hermann (2010). Teoría del Estado, Santiago, Fondo de Cultura Económica, pág. 260.

9 Pizorusso, Alessandro. (1984). Lecciones de Derecho Constitucional, Madrid, Centro de Estudios Constitucionales, pág. 25.

10 Valadés, Diego. (2002). Problemas Constitucionales del Estado de Derecho, México, Instituto de Investigaciones Jurídicas UNAM, pág. 20. Mirkine-Guetzévitch, Boris. (2013). Modernas tendencias del Derecho Constitucional, Madrid, Editorial Reus.

11 Las expresiones normativas del constitucionalismo social en la historia del derecho constitucional lo constituyen la carta de Querétaro de 1917 y la Constitución alemana de Weimar de 1919, en que se incorporaron en catálogo de derechos fundamentales los denominados «derechos sociales». 
la seguridad social y la salud, así como la consagración de los principios de equidad en las relaciones jurídicas y económicas ${ }^{12}$.

Ahora bien, el desenvolvimiento del Estado social tradicional reflejó, en lo referente al Estado de derecho y al sistema de derechos fundamentales, un positivismo legalista cuya idea matriz se fundaba en la omnipotencia del legislador y que se caracterizó por dos procesos que se desenvolvieron en paralelo y que terminaron desbordando - o más bien, superando- dicha influencia positivista ${ }^{13}$. Por un lado, la proliferación de «leyes medidas» ${ }^{14}$, esto es, la renuncia al concepto de la Ley como norma general para el ámbito de la administración prestacional cuya naturaleza jurídica específica regula directamente situaciones concretas. De este modo, las denominadas «leyes medidas» constituyeron los instrumentos normativos destinados a encauzar la intervención del legislador en la economía y sociedad, promoviendo los fines y objetivos propios del Estado social ${ }^{15}$. Por otro lado, el Estado social clásico que pretende garantizar la justicia social mediante políticas redistributivas con el fin de cubrir necesidad básicas y otorgar prestaciones sociales ${ }^{16}$, descansa en la nítida separación entre la potestad tributaria y la garantía de la propiedad, en la medida que el acceso del Estado al producto social y a los ingresos por medio de la potestad fiscal, se ejerce antes de que la propiedad privada se ampare en la órbita de protección que otorga la garantía del derecho a la propiedad en el Estado de derecho ${ }^{17}$. Este presupuesto del Estado social resulta indispensable para la actividad del legislador y la administración prestacional, en especial para implementar las medidas de distribución social que permitan superar la desigualdad social y establecer el denominado equilibrio social ${ }^{18}$.

Esta tendencia se tradujo, en cuanto a los derechos sociales, al reforzamiento de la intervención estatal, especialmente de la actividad administrativa de servicio

12 Valadés, Diego. (2002). Problemas Constitucionales del Estado de Derecho, México, Instituto de Investigaciones Jurídicas UNAM, pág. 20.

13 Una visión crítica del período y al «legalismo positiva», véase Mateucci, Nicola. (2010). El Estado Moderno: léxico y exploraciones, España, Unión Editorial, pág. 172.

14 La categoría de «ley-medida» fue acuñado críticamente por Forsthoff, que la conceptualizó como aquellas «(...) regulaciones subordinadas y servidoras de la realización de un fin. La ley-medida se desprende, por lo tanto, de una determinada situación, respecto de la cual, adopta una relación previsible y de comprensión lógica». Forsthoff, Ernest. (2015). Estado de Derecho en mutación. Trabajos constitucionales 1954-1973, Madrid, Editorial Tecnos, pág. 177. Zagrebelsky, Gustavo (1995). El derecho dúctil. Ley, derechos y justicia. Madrid, Editorial Trotta, pág. 37. En un sentido similar: Irti, Natalino. (1992) [1978]. La edad de la descodificación, Barcelona, Bosch, pág. 33.

15 Böckenförde, Ernst. (2000). Estudios sobre el Estado de Derecho y la Democracia, Madrid, Editorial Trotta, pág. 38 .

16 Así, además, lo criticaba Schmitt, Carl. Ver Schmitt, Carl (1955). «Apropiación, partición, apacentamiento» (traductor Antonio Truyol y Serra). Boletín Informativo del Seminario de Derecho Político No2, págs. 10-11

17 Forsthoff, Ernest. (2015). Estado de Derecho en mutación. Trabajos constitucionales 1954-1973, Madrid, Editorial Tecnos, págs.139-140.

18 Ibid., p. 39. 
público, la ampliación de la discrecionalidad del aparato público en el otorgamiento de prestaciones sociales y la producción constante de normas infralegales destinada a regular los ámbitos más diversos de la sociedad ${ }^{19}$. Esta propensión rampante a la «motorización legislativa ${ }^{20}{ }$, así como los procesos políticos, sociales y culturales en que se insertan los derechos fundamentales, incidieron en la configuración normativa de las libertades individuales y, especialmente, en el contenido de la propiedad privada en virtud del cual se trastocaba el paradigma y visión liberal de la propiedad, centrada en el individuo y proyectada hacia la sociedad. Este cambio de paradigma dio paso a un enfoque diverso en que legislador democrático - representante del interés general - se encuentra habilitado para limitar y regular el contenido del derecho de propiedad. Tal como nos recuerda un autor, este enfoque puso de relieve:

«[...] el lugar de los intereses colectivos o comunitarios para, sin desconocer los del titular del derecho, sostener la primacía de los mismos y reducir la libertad del propietario al espacio residual resultante (conforme, en todo caso, al interés general) ${ }^{21}$.

A partir de esta premisa del Estado (legislativo) social, la cual expresa la profunda transformación en la concepción del derecho de propiedad como consecuencia de las nuevas características económicas de la sociedad industrial, surge y se consagra una concepción «socializante» de la propiedad, asentada sobre la intensa dictación de leyes especiales ${ }^{22}$.

19 Pisarello, Gerardo. (2007). Los derechos sociales y sus garantías. Elementos para una reconstrucción, Madrid, Editorial Trotta, pág. 85. En el mismo sentido: Ferrajoli, Luigi. (2004). Derechos y garantías. La Ley del más débil, Madrid, Editorial Trotta, pág. 30. Tal como lo constata Ferrajoli, la ausencia de un desarrollo adecuado de las garantías normativas de los derechos sociales ha provocado: «t...) que el Estado social se desarrollase de hecho a través de una simple ampliación de los espacios de discrecionalidad de los aparatos administrativos, el juego no reglado de los grupos de presión y las clientelas, la proliferación de las discriminaciones y los privilegios y el desarrollo del caos normativo que ellas mismas denuncian y contemplan abora como 'crisis de la capacidad regulativa del derecho'».

20 Véase Schmitt, Carl. (1971). Legalidad y Legitimidad, Madrid, Aguilar. Chile no estuvo exento de este fenómeno de proliferación normativa. Tal como lo constata Cordero, entre las razones que tuvo la Comisión de Estudios de la Nueva Constitución para cambiar el sistema de competencias normativas establecido en la Constitución de 1925 fue el siguiente dato: «t...) desde 1926 a 1973, se aprobaron 13.893 leyes, de las cuales el 52\% (7.207) tuvo carácter individual, el 40\% (5.524) alcanzó a sectores, actividades, zonas o instituciones determinadas y el 8\% (1.162) fue de aplicación general». Cordero, Eduardo. (2009). «El sentido actual del dominio legal y la potestad reglamentaria». Revista de Derecho, Pontificia Universidad Católica de Valparaíso, Vol. 32, Nº1, pág. 418. Asimismo, véase en: Zúñiga, Francisco. (2009). «Los dilemas actuales de la función legislativa. El Congreso Nacional y su problemática centralidad-funcionalidad». Revista de Derecho Público, N71, pág. 68.

21 Cordero, Eduardo. (2006). «La dogmática constitucional de la propiedad en el derecho chileno». Revista de Derecho, Universidad Austral de Chile, Vol. XIX, N¹, págs. 125 - 148.

22 Rey, Fernando. (1994). La propiedad privada en la Constitución Española, Madrid, Centro de Estudios Constitucionales, págs. 104-105. Como nos recuerda el autor, desde una perspectiva normativa, lo más característico de la concepción colectivizante o socializante de la propiedad privada, fue, por un lado, la pérdida de centralidad del Código Civil en beneficio de leyes especiales, y por otro, el «giro

(C) UNED. Revista de Derecho Politico

N. ${ }^{\circ} 112$, septiembre-diciembre 2021, págs. 329-353 
A lo anterior se suman, cláusulas normativas que contemplan la posibilidad constitucional de la socialización de la tierra y del suelo, de los recursos naturales y de los medios de producción que pueden ser convertidos en propiedad colectiva, tal como sucede, por ejemplo, con el artículo 15 de la Ley Fundamental alemana de $1949^{23}$ o los artículos 42 y 43 de la Constitución italiana de $1947^{24}$. Dicha comprensión del derecho de propiedad no sólo comienza a perfilar paulatinamente un régimen jurídico objetivo de la propiedad, sino también, se adosan nuevas funciones estatales y se funcionaliza la propiedad privada a la necesidad sociales, para lo cual se utiliza como presupuesto legitimador de la intervención estatal en la propiedad la categoría de la función social ${ }^{25}$, como lo pasaremos a revisar más adelante. En la misma senda, avant la lettre, se sitúa la doctrina del servicio público de la Escuela de Burdeos en el derecho público francés de principio de siglo XIX y la concepción funcionalista de la propiedad.

\subsection{El tránsito del Estado social (legislativo) al Estado social y democrático de derecho}

La expansión del Estado social — principalmente en Europa-, trajo consigo un conjunto de tendencias de defección política e hipertrofia institucional, que, sumado a los ciclos de crisis económicas que afectaron al capitalismo industrial, las transformaciones tecnológicas y productivas, el declive de la socialdemocracia y el ascenso neoconservador durante la década de los 70’ y 80’ del siglo pasado, comenzaron a socavar las bases y puntos de apoyo del contrato constitucional sobre el cual se asentaba el Estado social tradicional ${ }^{26}$.

copernicano» que significó el estatuto jurídico de la propiedad privada que se consagraba en la Constitución de Weimar, siguiendo los pasos de la Constitución de Querétaro de 1917. Así, lo demuestra el artículo 153 de la la Constitución de Weimar.

23 Ley Fundamental de la República Federal Alemania. Traducción Prof. Dr. Ricardo García Macho, Universidad Jaime I (Castellón) y Prof. Dr. Karl-Peter Sommermann, Deutsche Hochschule für Verwaltungswissenschaften Speie, versión de 23 de mayo de 1949, con su última modificación al 23 de marzo de 2019, que trata en su artículo 15, los fines socializantes de la propiedad y el régimen de la propiedad colectiva.

24 Constitución de la República de Italiana. Senato della Repubblica, 2018, en particular el artículo 42 y el artículo 43 .

25 Cordero, Eduardo. (2006). «La dogmática constitucional de la propiedad en el derecho chileno». Revista de Derecho, Universidad Austral de Chile, Vol. XIX, N¹, págs. 125 - 148.

26 Pisarello, Gerardo (2001). «Del Estado Social Legislativo al Estado Social Constitucional: por una protección compleja de los derechos sociales». Isonomía, $\mathrm{N}^{\circ} 15$, pág. 87 . El mismo autor se encarga de describir el declive del Estado social clásico y la Constitución social mixta de postguerra, analizando la dimensión política-constitucional de la ofensiva desdemocratizadora y deconstituyente que emergió durante la década de los 70' y 80' del siglo pasado, junto con la emergencia de un «constitucionalismo neoliberal», en: Pisarello, Gerardo. (2012). Un largo Termidor: historia y crítica del constitucionalismo antidemocrático. Quito, Corte Constitucional para el período de Transición/Centro de Estudios y difusión del Derecho (CEDEC), págs. 165-189. Ver también: Pisarello, Gerardo. (2014). Procesos constituyentes. Caminos para la ruptura democrática. Madrid, Editorial Trotta, págs. 88 - 101 
Frente a las tensiones y crisis del Estado social, surge como respuesta un Estado social y democrático de derecho caracterizado por un renovado entendimiento sobre la Constitución, las atribuciones del legislador y el contenido de los derechos. En efecto, bajo el influjo de esta forma de Estado, se desplazó la definición clásica de la constitución como instrumento meramente procedimental o formal de arreglo del poder para ser reemplazado por una comprensión del texto constitucional de denso contenido normativo-material, a partir del cual se articulan garantías capaces de otorgar efectividad a sus disposiciones ${ }^{27}$. En ese sentido, el tránsito del Estado social tradicional a un Estado social y democrático, implicó tanto una reformulación de instituciones características de ciertos ordenamientos constitucionales así como la innovación de otras, delineando el panorama actual del Estado de derecho y alguna de sus notas normativas más características: la primacía de la Constitución sobre la ley, el principio de legalidad, la sumisión a la Constitución de la totalidad de los poderes públicos, publicidad y control del poder (público y privado), la justicia constitucional y la formulación de un sistema de garantías frente a los poderes públi$\cos y \operatorname{privados}^{28}$.

Estas transformaciones operadas en el Estado de derecho y en los ordenamientos constitucionales, sin duda impactaron en la comprensión y estructura del derecho de propiedad, así como en la posición que ocupa en el subsistema de derechos fundamentales, superando una comprensión limitada al mero conflicto entre intereses particulares, para develar las tensiones entre el interés privado del titular de la propiedad y el interés público de la colectividad, relativizando los alcances liberales- individualistas que se habían atribuido al instituto de la propiedad.

De esta manera, la tarea del legislador gendarme de la propiedad resulta desplazada por la acción de un legislador encargado de conformar mediante las normas correspondientes el derecho de propiedad determinando así su contenido concreto ${ }^{29}$. La función legislativa configuradora del régimen de propiedad, fundada en el interés general, supera la comprensión unitaria del concepto de propiedad, para dar paso a una «pluralidad de propiedades». Así, la evolución histórico-jurídica, traslada el derecho de propiedad a una posición diversa frente la Ley que asume una tarea reguladora del derecho, a la vez que actualiza su contenido, proceso potenciado por la cláusula de función social que se erige como el ámbito de mediación entre los intereses

27 Prieto Sanchís, Luis. (2004). «El Constitucionalismo de los derechos». Revista Española de Derecho Constitucional, año 244, N71, pág. 48. Véase también desde una perspectiva crítica Grasso, Paolo. (2003). El problema del constitucionalismo después del Estado Moderno, Madrid, Marcial Pons, págs. 57-60. En el mismo sentido, Pisarello, Gerardo (2001). «Del Estado Social Legislativo al Estado Social Constitucional: por una protección compleja de los derechos sociales». Isonomía, No 15, pág. 92 y Fernández-Miranda, Alfonso. (2003). «El Estado social». Revista Española de Derecho Constitucional, Año 23, N69, pág. 156.

28 Pereira Menaut, Antonio. (2003). Rule of Law o Estado de Derecho, Madrid, Marcial Pons, págs. 83-84.

29 Pizorusso, Alessandro. (1984). Lecciones de Derecho Constitucional, Madrid, Centro de Estudios Constitucionales, pág. 183.

(C) UNED. Revista de Derecho Politico

N. ${ }^{\circ} 112$, septiembre-diciembre 2021, págs. 329-353 
privados y la actividad pública, determinando el fin u objetivo que la propiedad privada debe cumplir en el sistema económico en que se inserte ${ }^{30}$.

A partir de la trayectoria histórica y normativa del instituto dominical, es posible deslindar e identificar una doble dimensión del derecho de propiedad, concepción dualista que se ha extendido al resto de los derechos fundamentales ${ }^{31}$. Así, se reconoce, por un lado, una dimensión subjetiva de la propiedad privada asociado al concepto de derecho subjetivo público y, por otro lado, una dimensión objetiva o institucional, ligada como ya hemos analizado, al régimen jurídico de la propiedad, la reserva de legislación y la función social y el establecimiento de regímenes dominicales sectoriales en materias de aguas, minas, caza, pesca, utilización de montes, etc., con el fin de garantizar y satisfacer los intereses públicos comprometidos, delineando el tránsito de la «propiedad-especulación» a la «propiedad-función ${ }^{32}$ ». De tal modo que, ambas dimensiones —objetiva o institucional y subjetiva_, responden a la historicidad y positividad de la categoría jurídica de la propiedad que permiten reconocer su contenido actual, así como la estructura y elementos que la caracterizan.

De ahí que, resulta indispensable abordar la dimensión histórica y la evolución constitucional de la regulación de la propiedad y del régimen de los bienes públicos, para luego abordar el contenido normativo y los alcances jurídicos de dicha regulación en el ordenamiento jurídico vigente en nuestro país que nos permita encuadrar y esbozar adecuadamente una propuesta sustantiva al debate constitucional.

\section{LA REGULACIÓN CONSTITUCIONAL DE LA PROPIEDAD Y EL RÉGIMEN JURÍDICO DE LOS BIENES PÚBLICOS}

\subsection{Antecedentes histórico - jurídicos del derecho de propiedad y de los bienes públicos en el ordenamiento constitucional}

Resulta necesario apuntar que el concepto de propiedad constituye una de las categorías normativas de mayor importancia en las legislaciones comparadas como resultado de su influencia decisiva en la organización de los sistemas políticos, económicos y sociales surgidos en cada época, preponderancia que no ha sido extraña a nuestro ordenamiento constitucional. Tal como ya se ha adelantado, la relevancia institucional de la propiedad explica de buena manera la intensidad de las

30 Cordero, Eduardo. (2008). «De la propiedad a las propiedades. La evolución de la concepción liberal de la propiedad». Revista de Derecho, Pontificia Universidad Católica de Valparaíso, Vol. 31, N², págs. 508-511.

31 Rey, Fernando. (1994). La propiedad privada en la Constitución Española, Madrid, Centro de Estudios Constitucionales, págs. 146 - 160.

32 Cordero, Eduardo. (2008). «De la propiedad a las propiedades. La evolución de la concepción liberal de la propiedad». Revista de Derecho, Pontificia Universidad Católica de Valparaíso, Vol. 31, N², pág. 511. 
innovaciones y cambios que han incidido en el concepto y en el contenido constitucional de la propiedad, dependientes del texto normativo de turno, así como del momento político y social que ha introducido modificaciones a la institución en estudio. Esta constatación resulta aún más pertinente si se considera el proceso constituyente en curso, en que las principales categorías e instituciones del sistema constitucional son sometidas a cambios e innovaciones.

En la historia constitucional chilena, es posible encontrar un primer antecedente de la regulación de la propiedad, en la Constitución de 1823, cuya reglamentación lata y dispendiosa, contrastaba con la mención puntual e inexacta del instituto dominical en el estatuto del Poder Judicial, consagrado en el Capítulo XII, específicamente en el artículo 117, que disponía al efecto: «A ninguno puede privarse de su propiedad, sino por necesidad pública, calificada por el Senado de notoriamente grave, y con previa indemnización ${ }^{33}$ ». Con la dictación de la Constitución de 1828, y en contraste con la Carta Política de 1823, se consagró la propiedad en el Capítulo III dedicado a los derechos individuales, incorporando a su contenido, el carácter inviolable de la propiedad, tal como se consagraba en el artículo 10, al disponer que la «La Nación asegura a todo hombre, como derechos imprescriptibles e inviolables, la libertad, la seguridad, la propiedad, el derecho de petición, y la facultad de Publicar sus opiniones», acercando paulatinamente el concepto de la propiedad a la categoría individualista y liberal del derecho - poder.

La Constitución de 1833, sucintamente, vino a regular la propiedad limitándose a reconocer su inviolabilidad, salvo los casos de expropiación. En ese sentido, su artículo 12 N5 disponía:

\section{«La Constitución asegura a todos los habitantes de la República:}

$6^{\circ}$ La inviolabilidad de todas las propiedades, sin distinción de las que pertenezcan a particulares o comunidades, i sin que nadie pueda ser privado de la de su dominio, ni de una parte de ella por pequeña que sea, o del derecho que a ella tuviere, sino en virtud de sentencia judicial; salvo el caso en que la utilidad del Estado, calificada por una lei, exija el uso o enajenación de alguna; lo que tendrá lugar dándose previamente al dueño la indemnización que se ajustare con él, o se avaluare a juicio de hombres buenos ${ }^{34}$ »

El eminente jurista liberal Jorge Hunneus, al interpretar el sentido y alcance de la disposición constitucional recién transcrita, y bajo la influencia de un iusnaturalismo racionalista imperante en la época, situó al derecho de propiedad como uno de los derechos naturales más importantes, en que destaca la protección de la titularidad de la propiedad, antes que su ejercicio, resaltando la protección de su contenido individual:

33 Roldán, Alcibíades. (1917). Elementos de Derecho Constitucional de Chile, Santiago-Valparaíso, Sociedad Imprenta - Litografía Barcelona, págs. 74 - 77.

34 Diario Oficial de la República de Chile. (20 I 5). Constituciones Políticas de la República de Chile. 1810-2015, Santiago, Diario Oficial de la República de Chile, pág. 232.

(C) UNED. Revista de Derecho Político

N. ${ }^{\circ} 112$, septiembre-diciembre 2021, págs. 329-353 
"Con los derechos naturales no sucede igual cosa. No tiene el legislador facultad para quitarlos a nadie. Violaría la lei natural, la justicia i la moral, si lo pretendiera. Lo único que es dado al legislador es determinar, i con perfecta claridad, las limitaciones a que esos derechos pueden sujetarse en su ejercicio (...)

Sólo dos limitaciones imponen el inciso que se examinamos al derecho de propiedad. La sentencia judicial i la expropiación por utilidad del Estado. La lei no podría, por consiguiente, establecer ninguna otra. En esto consiste la garantía que dicho inciso establece ${ }^{35}$ »

Esta comprensión del derecho de propiedad encuentra su desarrollo en las disposiciones del Código Civil de 1855, cuerpo legal aún vigente y de inminente cuño liberal e individualista, cuyo artículo 582 define al dominio como aquel: « $(.$.$) dere-$ cho real en una cosa corporal, para gozar y disponer de ella arbitrariamente; no siendo contra la Ley o contra derecho ajeno. La propiedad separada del goce de la cosa, se llama mera o nuda propiedad». Dicho poder jurídico, además de recaer sobre cosa corporal se extiende a las cosas incorporales, las cuales también puede ser objetos de derechos, como bien nos recuerda el artículo 583. A partir de dichas normas el legislador civil regula y disciplina latamente los aspectos fundamentales y las condiciones de ejercicio del instituto dominical, en contraste con el sucinto tratamiento que la Constitución vigente a la época de la dictación del Código Civil le dedicaba a la propiedad. Esta absoluta preminencia del derecho común de la propiedad permite explicar la vigencia sin solución de continuidad del texto del artículo $12 \mathrm{~N}^{\circ} 5$, el cual no sufrió modificaciones sino hasta la dictación de la Constitución de $1925^{36}$.

La Constitución de 1925, consagra en sus artículos 10, numeral 10 y 11, la inviolabilidad de todas las propiedades, la interdicción de la privación del dominio, si no es por sentencia judicial o mediante expropiación en razón de utilidad pública calificada por Ley y previa indemnización:

«10.o La inviolabilidad de todas las propiedades, sin distinción alguna.

Nadie puede ser privado de la de su dominio, ni de una parte de ella, o del derecho que a ella tuviere, sino en virtud de sentencia judicial o de expropiación por razón de utilidad pública, calificada por una lei. En este caso, se dará previamente al dueño la indemnización que se ajuste con él o que se determine en el juicio correspondiente.

El ejercicio del derecho de propiedad está sometido a las limitaciones o reglas que exijan el mantenimiento y el progreso del orden social, y, en tal sentido, podrá la lei imponerle obligaciones o servidumbres de utilidad pública en favor de los intereses jenerales del Estado, de la salud de los ciudadanos y de la salubridad pública;

35 Huneeus, Jorge. (1879). La Constitución ante el Congreso, Santiago, Imprenta de los Tiempos, págs. $43-54$.

36 Evans de la Cuadra, Enrique. (1967). Estatuto constitucional del derecho de propiedad en Chile, Santiago, Editorial Jurídica de Chile, págs. 11-12. 
11.o La propiedad exclusiva de todo descubrimiento o producción, por el tiempo que concediere la lei. Si ésta exijiere su expropiación, se dará al autor o inventor la indemnización competente37»

Como se desprende del texto recién citado, el constituyente de 1925 amplió la cobertura constitucional de bienes apropiables a toda clase de bienes «sin distinción alguna», y no sólo a las propiedades constituidas por muebles e inmuebles, como se podía deducir de la Constitución de $1833^{38}$. Asimismo, se introdujeron otras innovaciones consistentes en el reemplazo del concepto de «utilidad de Estado», como causal de justificación de la expropiación, por la de «utilidad pública», categoría jurídica más amplia en la cual quedan comprendidos los «intereses generales del Estado», la «salud de los ciudadanos» y la «salubridad pública». En ese sentido, como nos recuerda un autor:

»El ejercicio del derecho de propiedad está sometido a las limitaciones o reglas que exijan el mantenimiento y el progreso del orden social, y, en tal sentido, podrá la Ley imponerle obligaciones o servidumbres de utilidad pública en favor de los intereses generales del Estado, de la salud de los ciudadanos y de la salubridad pública» ${ }^{39}$.

De ahí que, estas innovaciones buscaron someter el ejercicio del derecho de propiedad a las «limitaciones y reglas que exijan el mantenimiento y el progreso social», otorgando a la Ley la facultad de imponer obligaciones al propietario, lo cual no era más que la expresión de la tendencia constitucional comparada en cuanto al entendimiento societal de la propiedad ${ }^{40}$. Ya lo señalaba un destacado autor, al analizar el precepto que se examina:

«(...) es menester considerar que el fundamento de estas limitaciones de conformidad con nuestra Constitución es el 'mantenimiento y el progreso del orden social', cuya calificación sólo es materia de Ley y que, esas limitaciones no significan ni una privación del derecho de propiedad, ni siquiera de todas las facultades inherentes al dominio, sino que son restricciones al ejercicio del derecho.

37 Diario Oficial de la República de Chile. (2015). Constituciones Políticas de la República de Chile. 1810 - 2015, Santiago, Diario Oficial de la República de Chile, pág. 275.

38 Capítulo X de la CPR de 1833. Ver, Carrasco, Sergio. (2002). "Génesis y Vigencia de los textos constitucionales chilenos», Santiago, Editorial Jurídica de Chile, págs. 116 - 117.

39 Evans de la Cuadra, Enrique. (1967). Estatuto constitucional del derecho de propiedad en Chile, Santiago, Editorial Jurídica de Chile, pág. 13.

40 Un parangón interesante es la Constitución de Bonn, la cual niega el carácter absoluto de la propiedad (su contenido y limitación quedan determinados por la ley, art. 14), aunque esta facultad encuentra una barrera en el art. 19, 2 (en ningún caso podrá ser afectado en su esencia un derecho fundamental). La primacía de la ley, como título valido para la intervención pública en la propiedad, se remota a los art. 74 y 75 de la introducción al Código general prusiano de 1794, los cuales disponían la precedencia del bien común por sobre los derechos individuales, estableciendo correlativamente la obligación estatal de indemnizar al particular que sacrifico su derecho de propiedad.

(C) UNED. Revista de Derecho Politico

N. ${ }^{\circ} 112$, septiembre-diciembre 2021, págs. 329-353 
La realización de la doctrina que consagra nuestra Constitución puede ser de positiva utilidad para los fines económicos sociales de nuestra democracia ${ }^{41} »$.

Las modificaciones antes señaladas, responden al debate que se suscitó con motivo del tratamiento constitucional del derecho de propiedad en la Subcomisión de Reforma designada por el presidente Arturo Alessandri. Así se desprende de las opiniones vertidas por el comisionado y Ministro, Ramón Briones Luco, subcomisionado de la época, quien explicó que el cambio en la redacción de la garantía del derecho de propiedad, en contraste con la formula contenida en la Constitución de 1833, buscaba atender las modificaciones que había sufrido el concepto de propiedad «[...] por las nuevas orientaciones sociales» ${ }^{42}$, por lo que señaló respaldar el que «[...] esta disposición debe ser modificada dejando establecido, en primer término, la idea de que la propiedad es una función social» ${ }^{43}$. Además, como lo recuerda un autor, lo que ya forma parte del anecdotario constitucional, durante el estudio de la reforma constitucional de 1925, el Presidente Arturo Alessandri, Duguit en mano, habría vencido las reticencias de los sectores liberales y conservadores, abriendo una brecha en la inviolabilidad de la propiedad obteniendo, en el inciso final del artículo 10, el reconocimiento implícito de la función social de la propiedad ${ }^{44}$.

Con posterioridad se sucedieron una serie de reformas legales y constitucionales que modificaron la fisonomía del estatuto y el régimen de la propiedad. Así, en 1963, se dicta la Ley $\mathrm{N}^{\circ} 15.295$, promulgatoria de reforma constitucional, que modificó sustancialmente el artículo 10, N¹0 de la Constitución Política de 1925, agregando dos importantes cambios: la primera, autorizaba a la toma de posesión material del bien expropiado, una vez dictada la sentencia de primera instancia, siempre que se hubiese reclamado del monto de la indemnización y que se tratare de expropiaciones para obras públicas de urgente realización o de predios rústicos. La segunda novedad,

41 Amunátegui, Gabriel. (1950). Manual de Derecho Constitucional, Santiago, Editorial Jurídica de Chile, pág. 370.

42 Visión que se ve confirmada en lo señalado por Heise González, Julio. (1954). Historia Constitucional de Chile, Santiago, Editorial Jurídica de Chile, pág. 135.

43 Ministerio del Interior de la República de Chile. (1925). Actas oficiales de las sesiones celebradas por la Comisión y subcomisiones encargadas del estudio del Proyecto de Nueva Constitución Política de la República, Santiago, Imprenta Universitaria, Sesión del 12 de mayo de 1925, págs. 85 - 86. A su vez, el comisionado Guillermo Guerra, señalaba en su intervención: «De todo lo que se ha dicho en esta reunión sólo se saca en limpio, en primer lugar, que debe reconocerse al derecho de propiedad un carácter más social. Aquello de si la propiedad es o no una función social, es un juego de palabras; en el fondo estamos de acuerdo en que ella debe estar más subordinada al interés social que lo que lo estuvo antes»: Ibíd., p. 87. Asimismo, Evans de la Cuadra, Enrique. (1967). Estatuto constitucional del derecho de propiedad en Chile, Santiago, Editorial Jurídica de Chile, pág. 14.

44 Ministerio del Interior de la República de Chile. (1925). Actas oficiales de las sesiones celebradas por la Comisión y subcomisiones encargadas del estudio del Proyecto de Nueva Constitución Política de la República, Santiago, Imprenta Universitaria, Sesión del 15 de mayo de 1925, págs.114-116. También en Andrade, Carlos. (1971). Elementos de Derecho Constitucional Chileno, $2^{\circ}$ Edición, Santiago, Editorial Jurídica de Chile, págs. 205 - 206. 
era la agregación de tres incisos nuevos que en síntesis autorizaban al Estado «[...] con el objeto de propender a la conveniente división de la propiedad rústica», expropiar por causa de utilidad pública predios rústicos abandonados o que estuvieren «[...] manifiestamente mal explotados y por debajo de las condiciones normales predominantes en la región para tierras de análogas posibilidades», debiendo darse previamente al propietario el $10 \%$ de la indemnización y permitiendo que se pagara el saldo en cuotas anuales iguales, en un plazo máximo de quince años, con el interés legal. Además, se creaban tribunales especiales a efectos de reclamar de la indemnización otorgada.

Luego, durante el gobierno de Eduardo Frei Montalva, se dictó la Ley N¹6.615 de 18 de enero de 1967, sin duda, uno de los cambios más relevantes operados en el régimen constitucional de la propiedad consagrado en la Constitución de 1925. La importancia de esta reforma constitucional radicó en la consagración de una reserva de Ley para el establecimiento de limitaciones y obligaciones al dominio con la finalidad de asegurar su función social. En efecto, la modificación en comento del artículo $10 \mathrm{~N}^{\circ} 10$, disponía que:

«La Ley establecerá el modo de adquirir la propiedad, de usar, gozar y disponer de ella $y$ las limitaciones y obligaciones que permitan asegurar su función social y hacerla accesible a todos. La función social de la propiedad comprende cuanto exijan los intereses generales del Estado, la utilidad y la salubridad públicas, el mejor aprovechamiento de las fuentes y energías productivas en el servicio de la colectividad y la elevación de las condiciones de vida del común de los habitantes. Cuando el interés de la comunidad nacional lo exija, la Ley podrá reservar al Estado el dominio exclusivo de recursos naturales, bienes de producción u otros, que declare de importancia preeminente para la vida económica, social o cultural del país. Propenderá, asimismo, a la conveniente distribución de la propiedad y a la constitución de la propiedad familiar ${ }^{45} »$.

En dicho texto se terminó de desarrollar el concepto de función social de la propiedad, que tibiamente se consagró en 1925, como elemento que permitía la limitación del dominio y el establecimiento de obligaciones o cargas que, en definitiva, tenían como fines el acceso universal a la propiedad y el aprovechamiento productivo de los bienes objeto de apropiabilidad, de manera de servir a la colectividad y al mejoramiento de la calidad de vida de los habitantes de la República. Este concepto, elaborado dogmáticamente por León Duguit, junto con destacar el concepto individual y subjetivo del derecho de propiedad, ligaba a su ejercicio un conjunto de obligaciones y cargas en favor de la comunidad (lo que se denomina, su dimensión o aspecto objetivo).

La reforma constitucional, además, reitera un principio general como lo es el derecho del expropiado a una indemnización, cuyo monto y condiciones de pago debían determinarse tomando en consideración los intereses de la colectividad y del expropiado, encargando a la Ley establecer el régimen para fijar la indemnización,

45 Diario Oficial de la República de Chile. (2015). Constituciones Políticas de la República de Chile. 1810 - 2015, Santiago, Diario Oficial de la República de Chile, págs. 302 - 303. 
regulando algunos supuestos especiales, en particular, tratándose de la expropiación de predios rústicos, en que la indemnización debía ser equivalente al avalúo vigente y pagadera una parte al contado y otra parte en un plazo no superior a 30 años, todo ello en la forma y condiciones que la Ley determine. En aquellos casos en que la expropiación se verificaba respecto de la pequeña propiedad rústica trabajada por su dueño o se tratase de la vivienda habitada por su propietario, se aplicaba la regla general, en que la indemnización debía pagarse previa expropiación.

Por último, la reforma constitucional habilitó a la Ley para incorporar al dominio nacional de uso público todas las aguas existentes en el territorio nacional. De este modo, las aguas sin dueño se incorporaban al dominio público por declaración de la ley. En el caso de expropiación, la reforma introdujo una excepción al régimen general de este instituto en la medida que los dueños de las aguas expropiadas podían continuar usándolas en calidad concesionarios de un derecho de aprovechamiento y sólo tendrían derecho a la indemnización cuando « (...) por la extinción total o parcial de ese derecho, sean efectivamente privados del agua suficiente para satisfacer, mediante un uso racional y beneficioso, las mismas necesidades que satisfacían con anterioridad a la extinción». De este modo, pese a la expropiación del derecho de propiedad sobre el derecho a las aguas, el afectado podrá seguir usándolas, aunque en otra calidad jurídica, es decir, no obstante perder el dominio de las aguas, mantenía su uso ${ }^{46}$.

En 1971, la reforma constitucional dictada conforme la Ley $\mathrm{N}^{\circ} 17.450$, profundizó los cambios a la regulación constitucional de la propiedad, expresando la decisión política de nacionalizar la gran minería del cobre y la compañía Minera Andina. Esta reforma, adicionó una definición permanente en materia de propiedad del Estado en el artículo $10 \mathrm{~N}^{\circ} 10$ de la Constitución de 1925, consagrando una cláusula de dominio público minero, así como las bases del régimen de exploración, explotación y aprovechamiento de la minería metálica, no metálica e hidrocarburos ${ }^{47}$.

Con el establecimiento de la dictadura cívico-militar se inicia una nueva etapa en la regulación jurídica del derecho de propiedad. Dicho período se inicia con el Acta Constitucional $\mathrm{N}^{\circ} 3$, de 1976, que estableció un nuevo catálogo de garantías de rango constitucional, y que en su artículo $1^{\circ}, \mathrm{N}^{\circ} 16$, señalaba en lo atingente al contenido y protección del derecho de propiedad, que:

«El derecho de propiedad en sus diversas especies sobre toda clase de bienes, corporales o incorporales. Sólo la Ley puede establecer el modo de adquirir la propiedad, de usar, gozar

46 Tapia Valdés, Jorge. (1966). «La reforma constitucional del derecho de propiedad». Revista de Derecho Público, N5/6, pág. 103. Cabe, además, agregar, que con la dictación de la Ley N¹6.640 o «Ley de Reforma Agraria» de 1967, se modificaron un conjunto de disposiciones del Código de Aguas de 1951, introduciendo, una nueva definición de derecho de aprovechamiento de agua como aquel « $(. .$. derecho real administrativo que recae sobre las aguas y que consiste en su uso con los requisitos y en conformidad a las reglas que prescribe el presente Código», en coherencia con la reforma constitucional que consagró las aguas como bienes de dominio público.

47 Diario Oficial de la República de Chile. (2015). Constituciones Políticas de la República de Chile. 1810 - 2015, Santiago, Diario Oficial de la República de Chile, pág. 318. 
$y$ disponer de ella y las limitaciones y obligaciones que permitan asegurar su función social. La función social de la propiedad comprende cuanto exijan los intereses generales del Estado, la seguridad nacional, la utilidad y la salubridad públicas, el mejor aprovechamiento de las fuentes de energía productiva para el servicio de la colectividad y la elevación de las condiciones de vida del comín de los habitantes. No obstante, nadie puede, en caso alguno, ser privado de su propiedad, del bien sobre que recae, o de alguno de los atributos o facultades esenciales del dominio, sino en virtud de Ley general o especial que autorice la expropiación por causa de utilidad pública o de interés social o nacional, calificada por el legislador ${ }^{48}$ ».

La citada preceptiva constitucional trajo consigo cambios sustantivos al régimen jurídico del derecho de propiedad que había sido establecido en la Constitución de 1925 , morigerando la influencia «socializante» o funcionalista del derecho y las tendencias destinadas a fortalecer la intervención legislativa y la prevalencia del interés general. En efecto, se redujeron a cinco años el plazo máximo de pago de la indemnización por expropiación y a diez años por caso de excepción constitucional; se eliminó toda referencia a la nacionalización y la reserva del Estado ${ }^{49}$, a la expropiación de predios rústicos, al dominio nacional de uso público de las aguas y a la facultad del legislador para modificar y dejar sin efecto los contrato - leyes. En dicho sentido, el inciso final del citado numeral 16 del artículo $1^{\circ}$ del Acta Constitucional $\mathrm{N}^{\circ} 3$, encargaba a un estatuto especial la regulación de todo lo concerniente « (...) a la propiedad minera y al dominio de las aguas», dejando subsistente en su artículo $4^{\circ}$ transitorio el inciso sexto del artículo 10 de la Constitución de 1925, que entregaba al legislador la atribución de reservar al dominio nacional de uso público todas las aguas existentes en el territorio nacional, hasta la dictación del mencionado estatuto especial. Posteriormente, mediante el decreto ley $\mathrm{N}^{\circ} 2.603$, de 1979 , se suprimió en el inciso final del artículo $1^{\circ}$ $\mathrm{N}^{\circ} 16$ del Acta Constitucional $\mathrm{N}^{\circ} 3$, la frase «y al dominio de las aguas» y se introdujo un nuevo inciso del siguiente tenor: "Los derechos de los particulares sobre las aguas, reconocidos o constituidos en conformidad a la Ley, otorgarán a sus titulares la propiedad sobre ellos».

De esta forma, se elimina toda referencia constitucional al dominio público de las aguas, cuya definición queda entregada a la Ley como un bien nacional de uso público y se transita paulatinamente a un (excepcional) sistema reforzado de protección constitucional de la titularidad privada de los derechos de aprovechamiento de agua,

48 Ibid., p. 371.

49 Vergara, Alejandro. (2004). «La summa divisio de bienes y recursos naturales en la Constitución de 1980»-Revista Ius Publicum, N¹2, págs. 105 - 126. El autor al analizar los antecedentes históricos jurídicos del art. 19. 23 de la CPR de 1980, se remite a lo que se denominó la «reserva estatal de bienes» contemplado en el art, $10 \mathrm{~N}^{\circ} 10$ de la CPR de 1925, instituto introducido por la Ley 16.615 y que establecía: "Cuando el interés de la comunidad nacional lo exija, la Ley podrá reservar al Estado el dominio exclusivo de recursos naturales, bienes de producción u otros, que declare de importancia preeminente para la vida económica, social y cultural del país». Posteriormente, en el art. 1 №15 inc. 2 del Acta Constitucional №3, a pesar de su inspiración no estatista, reproduce la facultad de la Ley para reservar al estado determinados bienes que carecen de dueño. Sin embargo, esta previsión de rango constitucional no tuvo ningún desarrollo legislativo, al ser reemplazada por la Constitución Política de 1980.

(C) UNED. Revista de Derecho Politico

N. ${ }^{\circ} 112$, septiembre-diciembre 2021, págs. 329-353 
régimen jurídico que se terminara de consolidar con la dictación del Código de Aguas de 1981, apuntalando las bases de un sistema de asignación basado en el mercado de derechos de aprovechamiento ${ }^{50}$.

Por otra parte, se restringió el alcance de la función social de la propiedad, las limitaciones u obligaciones impuestas por la Ley y se asoció la expropiación indemnizable con la mutilación de los atributos esenciales del dominio ${ }^{51}$.

Este contexto jurídico - político, sirvió como marco referencial para las tareas acometidas por la Comisión de Estudio de la Nueva Constitución (y de la Subcomisión de Derecho de Propiedad) y el Consejo de Estado, instancias encargadas de proponer un proyecto constitucional para ser presentado a la Junta Militar, que luego se consagraría en el texto de la Constitución autoritaria de 1980. En efecto, como nos recuerda un autor, citando las actas de la Comisión de Estudios de la Nueva Constitución y los informes del Consejo de Estado al Presidente de la República, los fines y objetivos de la regulación constitucional de la propiedad que se estaba forjando, comprendían:

"1 $1^{a}$ Robustecer la garantía del derecho de propiedad y amparar sus atributos esenciales.

$2^{a}$ Admitir que la propiedad puede ser objeto de limitaciones y obligaciones para cumplir su función social, pero sin que ello pueda, en caso alguno, afectar a la esencia del derecho de dominio, $y$

$3^{a}$ Exigir que toda expropiación, autorizada siempre por ley, el pago de la indemnización total, al contado y en dinero, como requisito previo, anterior a la toma de posesión material de bien expropiado ${ }^{52}$ ».

Los cambios propuestos por la Comisión de Estudios de la Nueva Constitución de la dictadura incorporaban a la garantía del derecho de propiedad el plazo máximo para el pago de cualquier indemnización (cinco años), la regulación de la propiedad minera y el derecho exclusivo del Estado para explorar y explotar las sustancias minerales que la Ley señalare ${ }^{53}$. A su vez, el Consejo de Estado, modificó y restringió la

50 Vergara, Alejandro. (1998). Derecho de Aguas, Tomo II, Santiago, Editorial Jurídica de Chile, págs. 314-318. El autor, al analizar la legislación de aguas en el período 1979 a 1981, junto con destacar la consagración de un nuevo sistema de derechos de aguas, apunta, entre las principales características de dicha legislación: 1) reforzamiento de los derechos privados dirigidos al aprovechamiento de las aguas, 2) la libertad para transferir estos derechos, 3) la total libertad para el uso del agua, sin perjuicio de los límites relativos a la cantidad de agua que se puede extraer desde la fuente natural, 4) la inexistencia de usos prioritarios del agua, 5) la gratuidad para obtener y mantener la titularidad privada y 6) las limitadas facultades del órgano administrativo (Dirección General de Aguas) en la distribución del agua o en la resolución de conflictos.

51 Verdugo, Mario, Pfeffer, Emilio y Nogueira, Humberto. (1994). Derecho constitucional. Tomo I, Santiago, Editorial Jurídica de Chile, págs. 304 - 306.

52 Evans de la Cuadra, Enrique. (1999). Los derechos constitucionales. Tomo III, Santiago, Editorial Jurídica de Chile, págs. 230 - 231.

53 Ibid., p. 225. 
nómina de bienes jurídicos comprendidos en la función social del dominio y dispuso la forma en el pago de la indemnización por expropiación, la cual debía pagarse en dinero en efectivo y al contado, antes de la toma de posesión material del bien expropiado. Finalmente, la Junta Militar al considerar los cambios introducidos por el Grupo de Trabajo que designó, reforzó la propiedad o dominio público minero por razones geopolíticas o de seguridad nacional, y amplió la cobertura constitucional de la garantía de la propiedad a la concesión minera ${ }^{54}$.

El texto definitivo de la Constitución Política de la República de 1980 destaca por la centralidad de la institución de la propiedad privada en el catálogo de derechos fundamentales al regular el derecho a la propiedad (acceso) en su artículo 19 No23 y el derecho de propiedad (garantía) en el artículo $19 \mathrm{~N}^{\circ} 24$.

La actual redacción del estatuto constitucional de propiedad que se consagra en el artículo 19 N²4 de la CPR, encarga a la Ley la determinación de las eventuales limitaciones y obligaciones al ejercicio de las facultades que confiere el derecho de propiedad a los particulares, con fundamento en la garantía de la función social de éste. Sin perjuicio de ello, al mismo tiempo que se garantiza la propiedad, se restringe el alcance de dicha función social en comparación con los antiguos textos constitucionales, puesto que ella ahora sólo comprende «[...] los intereses generales de la Nación, la seguridad nacional, la utilidad y la salubridad públicas y la conservación del patrimonio ambiental»; aunque tal restricción es más bien nominal, en la medida que todos estos conceptos son los que, de antaño, la doctrina española denomina: «conceptos jurídicos indeterminados». Por otra parte, se insiste en el hecho que la expropiación no sólo comprende la privación del dominio de los bienes, sino que también de los atributos o facultades esenciales del dominio (uso, goce y disposición), lo que ha servido para justificar la declaratoria de inconstitucionalidad de medidas que vulnerarían dicho núcleo esencial.

Como se desprende de lo hasta aquí analizado, la comprensión y el entendimiento dogmático de las disposiciones constitucionales relativas al derecho de propiedad y el estatuto de los bienes públicos (que poseen su impronta ideológica, nítida en la «Constitución» de 1980 como es el cuño neoliberal), responden a un desarrollo histórico-constitucional determinado que han influido en el contenido y alcance de ambas instituciones. Una vez realizada esa tarea, es menester analizar el actual estatuto constitucional de los bienes públicos en nuestro país con el fin de analizar su contenido y su proyección en el ordenamiento jurídico, frente a los desafíos de un nuevo texto constitucional.

\subsection{El fundamento constitucional de los bienes públicos y el derecho a la propiedad}

En los numerales 23, 24 y 25 del artículo 19 de la CPR se condensan los principios y reglas que configuran y determinan el régimen constitucional de la

54 Ibid., pp. $225-226$.

(C) UNED. Revista de Derecho Político 
propiedad, los estatutos públicos y privados de dicho instituto, así como las condiciones generales de apropiabilidad, afectación, garantías y limitaciones de la propiedad ya adquirida. Con la finalidad de establecer el contenido, sentido y el alcance que poseen dichas normas, en particular, de los citados numerales $23 \mathrm{y}$ 24, la jurisprudencia constitucional ha distinguido, por un lado, el derecho a la propiedad y el derecho de propiedad. En efecto, como nos recuerda el Tribunal Constitucional (en adelante, TC):

«(...) la Constitución Politica ba becho una diferenciación entre el acceso a la propiedad y el ejercicio del derecho de dominio, destinado para cada uno de estos ámbitos dos diferentes numerales del artículo 19: el 23 para el primero y el 24 para el segundo. De ello también se concluye que, para establecer 'limitaciones o requisitos para la adquisición' ha exigido que sólo pueda hacerse por medio de una Ley de quórum calificado; y que, para establecer 'limitaciones $u$ obligaciones' que se deriven de la función social de la propiedad, ha preceptuado que sólo pueda bacerse por Ley sin adicional requerimiento de quórum ${ }^{55}$ "

Dicha diferenciación nos permite realizar una primera aproximación al contenido o ámbito de protección de las normas constitucionales en comento: mientras el numeral 23 garantiza el acceso a la propiedad privada, estableciendo, por un lado, la exclusión de ciertos bienes de cualquier tipo de propiedad, y por otro, la reserva de los bienes públicos de titularidad estatal; el numeral 24 resguarda el derecho de la propiedad ya adquirida y el instituto expropiatorio, consagrando las limitación, obligaciones y cargas a las cuales se encuentra sometida como consecuencia de su función social ${ }^{56}$.

Ahora bien, en atención al objeto de la presente monografía, centraremos nuestro análisis sobre el numeral 23 del artículo 19 de la CPR, ya que no sólo regula el ámbito de protección de la libertad fundamental para adquirir toda clase de bienes, sino también, el régimen jurídico del dominio público en nuestro país. De ahí que, resulte ineludible abordar su dimensión constitucional.

\subsection{El artículo $19 N^{\circ} 23$ de la CPR: el ámbito de protección del derecho fundamental}

El objeto de esta garantía es asegurar el libre acceso, a fin de hacer ingresar al dominio privado de las personas, a cualquier título lícito, toda clase de bienes sean muebles o inmuebles, corporales o incorporales, y en general, de todas las cosas susceptibles de ser incorporadas a un patrimonio personal, de forma de proteger a las personas de los actos emanados de los poderes públicos — principalmente, el poder legislativo y la Administración - de impedir o entrabar el libre acceso a alguna categoría de bienes. Así se desprende del texto de la disposición constitucional que

55 STC, Rol N¹15-90, 3 de noviembre de 1990, C. $25^{\circ}$.

56 Cea Egaña, José Luis. (2012). Derecho Constitucional Chileno. Tomo II, Santiago, Ediciones Universidad Católica de Chile, pág. 556. 
consagra la garantía constitucional de acceso a la propiedad, en particular, la primera parte del inciso primero del artículo $19 \mathrm{~N}^{\circ} 23$ de la CPR:

«La libertad para adquirir el dominio de toda clase de bienes, excepto aquellos que la naturaleza ha hecho comunes a todos los hombres o que deban pertenecer a la Nación toda y la Ley lo declare así. Lo anterior es sin perjuicio de lo prescrito en otros preceptos de esta Constitución.

Una Ley de quórum calificado y cuando así lo exija el interés nacional puede establecer limitaciones o requisitos para la adquisición del dominio de algunos bienes»

Para literatura constitucional. el contenido de este derecho fundamental comprende la facultad de toda persona para la adquisición de bienes, sean estos muebles o inmuebles, corporales o incorporales, salvo el caso de las prohibiciones y limitaciones previstas expresamente en la Constitución ${ }^{57}$. En dicho sentido, el contenido sustantivo de esta libertad se traduce en la posibilidad cierta y real de que los particulares puedan acceder al dominio de las cosas corporales e incorporales, ya sean bienes de consumo o de producción, que les permitan a las personas individuales y a las organizaciones intermedias alcanzar sus finalidades propias ${ }^{58}$. Lo anteriormente señalado es coherente con la preferencia de la Constitución de 1980 y de sus redactores por resaltar el acceso de los individuos a la propiedad privada tal como se desprende del precepto constitucional en la comisión que asesoró a la dictadura cívico-militar ${ }^{59}$ y ha sido reafirmado por la jurisprudencia constitucional ${ }^{60}$.

En efecto, como ya se ha adelantado, el origen de esta norma en el Acta Constitucional $\mathrm{N}^{\circ} 3$ dictada por decreto ley $\mathrm{N}^{\circ} 1.552$ publicado el 13 de septiembre de 1976, en particular, en su inciso final. El precepto del Acta Constitucional aseguraba a todas las personas:

57 Nogueira, Humberto. (2008). Derechos Fundamentales. Tomo IV. Santiago, Editorial Librotecnia, págs. 168 - 169 .

58 Montt, Santiago. (2002). El dominio público. Estudio de su régimen especial de protección y utilización, Santiago, LexisNexis, págs. 218-219.

59 República de Chile. (1975). Actas Oficiales de la Comisión Constituyente, Santiago, Biblioteca Nacional del Congreso, Sesión 148 a martes 26 de agosto de 1975. Así se desprende de las intervenciones de los invitados a la Subcomisión de Derecho de Propiedad, Julio Philippi y Pedro Jesús Rodríguez. Por ejemplo, Pedro Jesús Rodríguez, en discusión, con el señor Phillippi, expresó: « .... łal derecho a la propiedad pueden asignársele dos significados: uno, desde el punto de vista propiamente jurídico, que en un sentido subjetivo se identifica o relaciona con la capacidad de adquirir, esto es, con el atributo de la personalidad que permite tener acceso a la propiedad y que, en consecuencia., es un presupuesto o requisito previo para la adquisición, y que en un sentido objetivo se vincula con la comerciabilidad de los bienes, esto es, con su aptitud para ser apropiados; y, en otro orden, el precepto sobre este derecho puede entenderse con un carácter más bien de política social, en cuanto tiende a estimular el acceso a la propiedad de las personas más desposeídas de la colectividad»

60 Por ejemplo, véase las sentencias: STC, 5.045-2018, de 20 de junio de 2019, C.8 ${ }^{\circ}$ y STC, Rol N॰8614-2020, 12 de noviembre de 2020, C.6º

(C) UNED. Revista de Derecho Político

N. ${ }^{\circ} 112$, septiembre-diciembre 2021, págs. 329-353 
«(...) Para promover el acceso de un mayor número de personas al dominio privado, la Ley propenderá a una conveniente distribución de la propiedad y a la constitución de la propiedad familiar»

Por su parte, la Comisión de Estudios de la Nueva Constitución de la dictadura entendió el derecho a la propiedad como la posibilidad jurídica de adquirir el dominio o de ser titular de toda forma de propiedad cuyo propósito político no era otro que promover y reforzar la existencia de un régimen general de apropiabilidad privada y que sirva de límite objetivo al dominio público ${ }^{61}$. En ese sentido, el fundamento del denominado «derecho a la propiedad» explicita la libertad de acceso que facilita y permite que la persona se convierta en propietario, configurando una facultad de apropiabilidad de los particulares de los bienes que no se encuentras sujetos a reserva constitucional. Si bien, originalmente, en la redacción de la norma constitucional, se exigía una acción del Estado de carácter distributivo de la propiedad existente - que perseguía mantener cierta continuidad normativa con el texto constitucional de 1925 , reformado en $1967^{62}$ - dicho objetivo inicial fue abandonado para reforzar el acceso jurídico de carácter individual a la propiedad ${ }^{63}$.

Los antecedentes históricos del precepto constitucional han resultado coincidentes con la interpretación que los tribunales de justicia han realizado del contenido del precepto constitucional en análisis. Así, la jurisprudencia de la Corte Suprema, en alusión al sentido y alcance de la norma iusfundamental, ha señalado como finalidad del artículo $19 \mathrm{~N}^{\circ} 23:$ (...) proteger a las partes de actos legislativos o de autoridad que excluyan de este libre acceso a alguna categoría de bienes, salvo las excepciones contempladas en la misma norma constitucional ${ }^{64}$ »

Por su parte, el Tribunal Constitucional ha relevado la preferencia del constituyente por la propiedad privada frente al dominio público, desplazando a este régimen

${ }^{61}$ Ibid. A modo de ilustración, el comisionado Rodríguez señaló sobre la nueva disposición constitucional: "(...) la ventaja que presenta un precepto sobre la garantía al derecho a la propiedad consistiría en precaver la eventualidad de que, por efecto de una norma legal sobre la comerciabilidad de los bienes o sobre la capacidad de las personas para adquirirlos, se produjeran alteraciones sustanciales al régimen de propiedad privada; pero, en tal caso, sería necesario reconocer constitucionalmente la capacidad de goce de toda persona y disponer que el legislador no pueda declarar incomerciables determinados bienes».

${ }_{62}$ Cabe recordar, como ya se indicó, que la Ley $\mathrm{N}^{\circ} 16.615$ de 20 de enero de 1967, constituye uno de los más relevantes cambios operados en el régimen constitucional de la propiedad establecido en Constitución de 1925 en su artículo 10. Su importancia radica en la consagración de una reserva de Ley para el establecimiento de limitaciones y obligaciones al dominio con la finalidad de asegurar su función social y en el deber legal de propender a la «[...] conveniente distribución de la propiedad y a la constitución de la propiedad familiar».

63 Fermandois, Arturo. (2014). Derecho Constitucional Económico. Tomo II, Santiago, Ediciones Universidad Católica, pág. 234. Véase también, Evans de la Cuadra, Enrique. (1999). Los derechos constitucionales. Tomo III, Santiago, Editorial Jurídica de Chile, pág. 171.

64 Sentencia de la Corte Suprema, 26 de mayo de 1988. Revista de Derecho y Jurisprudencia, t. 85 , sec. $5^{\text {a }}$, p. 186. 
de bienes a una posición excepcional en nuestro sistema constitucional. En efecto, en palabras del Tribunal:
«(...) los bienes nacionales de uso público son una excepción. La regla general es que los bienes puedan ser adquiridos por los privados o incluso por los órganos estatales. En este último caso, estamos frente a los bienes de dominio patrimonial del Estado o simplemente bienes fiscales. Estos forman parte del patrimonio de una persona administrativa (Fisco, servicios públicos des- centralizados, municipios, gobiernos regionales, etc.) (...) El carácter excepcional del dominio público trae aparejada una importante consecuencia: 'Si bien puede admitirse que, en principio, cualquier tipo de bienes puede integrar el dominio público —inmuebles y muebles, materiales e inmateriales-, es necesario enseguida corregir dicha afirmación, por cuanto dicho planteamien- to tan amplio no es permitido por la Constituciónt ....) " ${ }^{65}$.

Predicamento que ha sido reiterado en una reciente sentencia del Tribunal Constitucional, al inferir del artículo $19 \mathrm{~N}^{\circ} 23$ del texto constitucional una regla general consistente en la libre apropiabilidad de los bienes y una regla excepcional en el dominio público, señalando «De este modo la Constitución, recogiendo las categorías del Código Civil con ligeras modificaciones, reconoce que ciertos bienes no son apropiables por los particulares, siendo la regla general la libre apropiabilidad en materia de adquisición de bienes ${ }^{66}$ ".

Despejada la interpretación histórica del precepto constitucional y la finalidad de la libertad para adquirir el dominio de toda clase de bienes, es posible dilucidar su contenido normativo. Para ello, y siguiendo a la doctrina nacional y la jurisprudencia constitucional, es posible identificar dos dimensiones de este derecho fundamental que determinan su alcance ${ }^{67}$. Por un lado, una dimensión negativa, que impide y prohíbe el establecimiento de obstáculos abusivos que limiten excesivamente el acceso y adquisición a todo tipo de propiedades. Por otro lado, esta libertad contempla una dimensión positiva, la cual se traduce en el establecimiento de incentivos y en la consagración normativa para adquirir la propiedad de bienes o derechos ${ }^{68}$.

Ambas dimensiones configuran el objeto de protección del derecho a la propiedad que comprende un haz de facultades y garantías en favor de las personas naturales o jurídicas, tales como la libertad de adquisición de toda clase de bienes existentes, siempre que sean susceptibles de apropiación privada, salvo las excepciones reguladas en la legislación civil y en la normativa constitucional y el énfasis defensivo de esta libertad frente a la intervención de los actos legislativos o de cualquier otro poder público que impida u obstaculice su ejercicio legítimo, sin perjuicio del

65 STC, Rol N¹.281-2008, 13 de agosto de 2009, C.30.

66 STC, Rol N8.614-2020, 11 de noviembre de 2020, C.6º.

67 Bronfman, Alan, Martínez Estay, José y Núñez Poblete, Manuel. (2012). Constitución Política Comentada. Parte dogmática, Santiago, Abeledo Perrot, pág. 394

68 STC, Rol Nº1.298-2009, 3 de marzo de 2010, C. 39 . En el mismo sentido, STC, Rol $\mathrm{N}^{\circ} 2.912-2015,27$ de diciembre de 2016, C. $23^{\circ}$.

(C) UNED. Revista de Derecho Politico 
establecimiento de limitaciones y requisitos por ley, en la medida que no se verifique la afectación al contenido esencial del derecho ${ }^{69}$.

El régimen jurídico de la libertad de adquisición de toda clase de bienes y sus reglas particulares, que se desprenden de la norma constitucional y los desarrollados de la doctrina y la jurisprudencia constitucional ${ }^{70}$, se completan con las limitaciones y excepciones establecidas por la Constitución a la garantía general de apropiabilidad. Estos límites constitucionales no sólo cumplen una función delimitadora del derecho fundamental, sino también configuran el dominio público cuyo fundamento normativo se reconduce directamente a la Constitución y se desarrolla en la ley, tal como pasaremos a revisar y analizar en la segunda parte de esta monografía.

Title:

Public goods, private property and new Constitution (first part)

\section{Summary:}

I. INTRODUCTION: THE TRANSFORMATIONS OF THE STATE OF LAW, THE LEGAL REGIME OF PROPERTY AND PUBLIC GOODS. 1.1. From the liberal State of law to the social State of law. 1.2. The transition from the social (legislative) State to the social and democratic State of law. II. THE CONSTITUTIONAL REGULATION OF PROPERTY AND THE LEGAL REGIME OF PUBLIC GOODS. 2.1. Historical and legal background of the right to property and public goods in the constitutional order. 2.2. The constitutional basis of public goods and the right to property. 2.3. Article $19 \mathrm{~N}^{\circ} 23$ PCR: the scope of protection of the fundamental right. III. THE CONSTITUTIONAL LIMITATION ON THE FREE APPROPRIATION OF PROPERTY AND THE PUBLIC DOMAIN IN THE CONSTITUTION. 3.1. Historical-legal background of the constitutional regulation of public goods. 3.2. The legal regime of public goods and their reception in the current Constitution. 3.3. On the concept and legal nature of the public domain. 3.4. The characteristic elements of the public domain and the categories of public domain goods. IV. PUBLIC GOODS AND DEMANIAL CONCESSION. 4.1. Grant or permit demanial: concept and classification. 4.2. Featuring notes. V. CONSTITUENT POWER, OWNERSHIP AND LEGAL REGIME OF

69 Fermandois, Arturo. (2014). Derecho Constitucional Económico. Tomo II, Santiago, Ediciones Universidad Católica, pág. 235.

70 STC, Rol No1.988-2011, 24 de junio de 2011, C. $27^{\circ}$. 
PUBLIC GOODS. 5.1. Concept, ownership and legal nature of the constituent power. 5.2. New Constitution and the regime of concessions on NAPU: scope and effects. VI. CONCLUSIONS.

\title{
Resumen:
}

Este artículo aborda sucintamente una evolución del derecho de propiedad y de los bienes públicos en las constituciones de Chile, así como el surgimiento de la función social. Además, aborda los tipos de bienes privados y públicos, tipos de propiedad y los términos teórico-prácticos de esta cuestión. Por otra parte, este trabajo define el dominio público, sus características y el régimen de permisos y concesiones que permite la explotación privada de los bienes públicos.

Finalmente se enfoca la cuestión prospectivamente en el marco del debate constituyente en torno a la nueva Constitución que Chile aprobará en el año 2022. Para los autores, el poder constituyente originario desatado en noviembre de 2019 permite un amplio abanico de reconfiguración del derecho de propiedad y de los bienes públicos; subordinando la propiedad y los bienes privados al interés general de la nación.

\begin{abstract}
:
This article briefly addresses an evolution of property rights and public goods in the Chilean constitutions, as well as the emergence of the social function. In addition, it addresses the types of private and public goods, types of property and the theoretical and practical terms of this topic. On the other hand, this work defines the public domain, its characteristics and the system of permission and concessions that allow the private exploitation of public goods.

Finally, the issue is approached prospectively within the framework of the constituent debate around the new Constitution that Chile will approve in 2022. For the authors, the original constituent power unleashed in November 2019 allows a wide range of reconfiguration of property rights and of public goods; subordinating property and private goods to the general interest of the nation.
\end{abstract}

\section{Palabras claves:}

Propiedad, función social, bienes públicos, bienes privados, permisos y concesiones, poder constituyente originario y nueva Constitución.

\section{Keywords:}

Property, social function, public goods, private goods, permissions and concessions, originally constituent power and new Constitution. 